\title{
HIGHER EDUCATION AS A FACTOR FOR ECONOMIC DEVELOPMENT OF THE REGIONS IN BULGARIA
}

\author{
R. Angelova* \\ PhD student, Faculty of Economics, Sofia University "St. Kliment Ohridski", Sofia, Bulgaria
}

\begin{abstract}
The article analyzes the educational structure of the population at a regional level as a factor for growth. It compares the impact of education (with a particular focus on higher education) and the impact of other factors on the economic development of the regions (direct foreign investment, number of nonfinancial corporations per 1000 people, costs of acquiring tangible fixed assets per capita in BGN), number of students in colleges and universities per 1000 people, value of paid amounts under contracts of municipalities within the administrative area as beneficiaries under operational programs, $\mathrm{BGN} /$ person). Each of these indicators is compared with the role of higher education graduates at regional level for economic growth by looking not only at individual effects but also in the aggregate effects of these indicators. The analysis presents the dynamics of each indicator and the distances between the regions (compared to the maximum - the region with the highest values and the country average). The analysis presents whether there has been a convergence between the regions over the years or, the contrary - deepening differences between them. The article highlights the ideal mix of factors, needed for successful regional economic development and its supporting policies.
\end{abstract}

Key words: economic growth at regional lever; education as a factor for growth; a convergence between regions; cohesion; economic development; regional policies for growth;

\section{INTRODUCTION}

One of the big issues faced by scientists and politicians is what are the factors of economic growth and what growth-boosting policies can be implemented by individual governments and local authorities. The scientific debate on these issues is very intense and scientists do not agree on what are the basic prerequisites for achieving economic growth. According to the ten recommendations, developed in the Washington Consensus, fundamental to economic growth are: 1) the right to private property, protected and without risk of being seized arbitrarily, 2) macroeconomic stability, 3) free market. In response to this, scientists such as Haussmann, Rodrik and Velasco (1) raise the question that many Asian countries achieve economic growth without their societies and economies being in line with what the recommendations of the Washington Consensus are. Spence (2) tries to distinguish the factors of growth of the economy in a different social context by looking at developing and developed countries and takes

\footnotetext{
*Correspondence to: Radostina Angelova, PhD student, Sofia University "St. Kliment Ohridski", Faculty of Economics, Sofia 1000, 113 Knyaz Boris Istr., radost_angelova@yahoo.com
}

into account such factors as the availability or not of natural resources. The Spence study shows that education and inclusive growth are just as important as the market. Other scientists, such as Aghion (3) and Howitt (4), believe that accumulated capital and innovation are key to growth. In the context of innovation, they also address the role of education as an important factor in the development of R\&D and innovation.

\section{METHODOLOGY}

This article analyzes the educational structure of the population at a regional level as a factor for growth. It compares the impact of education (with a particular focus on higher education) and the impact of other factors on the economic development of the regions (direct foreign investment, number of nonfinancial corporations per 1000 people, costs of acquiring tangible fixed assets per capita in BGN), number of students in colleges and universities per 1000 people, value of paid amounts under contracts of municipalities within the administrative area as beneficiaries under operational programs, BGN/person). Each of these indicators is matched by the role of higher education graduates at regional level for economic growth by looking not only at 
individual effects but also in the aggregate effects of these indicators. In summary, the article highlights the ideal mix of factors, needed for successful regional economic development and its supporting policies.

The first part of the analysis presents the dynamics of each indicator and the distances between the regions (compared to the maximum - the region with the highest values and the country average). This analysis tracks whether there has been a convergence between the regions over the years or, the contrary deepening differences between them. The geographic and economic context in which the regions are located and the impact of such factors as key infrastructure, demographic structure of the population, etc. are also analyzed. In the second part, the individual indicators are examined in terms of their impact on economic growth at regional level.

\section{RESULTS AND DISCUSSION}

In the 2000-2015 period, the following trends in economic and social development of the regions in Bulgaria are present:

- At the end of the survey period, a high concentration of the economy is observed in a few large cities. In practice, from a comparatively convergent position at the beginning of the period, there is a highly visible distance between the regions at the end. This trend is observed both by regional GDP data and by the trends in the average number of non-financial enterprises per 1 000 people.

- In 2014 only three cities have GDP per capita above the national average, while in 2000 their number was 5 , with additional 4 being very close to the country's average GDP per capita. At present, 10 of the administrative districts have a GDP per capita below the national average of more than $40 \%$. For another 10, the GDP gap is more than $25 \%$, and only 5 areas have GDP per capita, which is only $15 \%$ and $20 \%$ lower.

- As of 2014, the number of non-financial enterprises per 1000 people is close to or above the national average in just 6 regions. In all other areas the number of nonfinancial enterprises is smaller and the distances are large - for 10 regions the difference with the average indicator for the country (number of non-financial enterprises) is above $30 \%$. By comparison, at the beginning of the surveyed period, in 2000 , the areas where the number of nonfinancial enterprises per 1000 people was close to the average for the country were 13.

- An even greater concentration is observed in terms of foreign direct investment and fixed asset costs. In the beginning of the period, there were regions with good positions in this indicator (Gabrovo, Lovech), but a strong decline was observed at the end of the period, as the share of foreign direct investment in them in 2014 decreased and their positions remained well below the average the country.

- As a result of the reduced FDI and fixed asset costs, parallel to the declining number of enterprises per capita, the employment and unemployment rates in the regions show dynamic changes, while the regions with good indices decrease two times.

- The share of people with higher education in the age group 25-64 increases in all administrative areas, but the growth rates in some of them are slowing down (Haskovo, Targovishte, Lovech, Gabrovo).

- There's growth in the role of some regional university centers (Veliko Tarnovo, Plovdiv, Stara Zagora, Smolyan, Yambol, etc.), where the ratio of college and university students in 1000 people increases, while at the same time there is a slight decrease in the position of Sofia, which hands over the first place of this indicator to Veliko Tarnovo. Although this indicator is influenced by population decline due to demographic processes and migration, there are still trends that deserve attention and which can affect local economic development.

Against these trends and with different socioeconomic, demographic and geographic features, the regions are in a very different situation, with a tendency for these distances to increase. This naturally raises the question of which policies for promotion of local economic development need to be developed and lead individual regions to improve their status.

By comparing a series of indicators and their correlation with the GDP per capita indicator at regional level, it is clear that the correlation is strongest in the higher education indicator, as throughout the years, the Pearson Correlation ranges between 0.774 and 0.831 at a level of significance,000 (Sig. (2-tailed), ie the regions with the highest share of graduates in the population between 25 and 64, have the highest GDP per capita, the highest being the correlation values in 2010 when the rate of increase in the proportion of graduates is 
increasing (Figure 1). This is the stage where the pace of GDP growth starts to increase. But as a whole, we are observing an increasing correlation, the role of education in boosting local economic growth is growing. Another important factor that strongly correlates with economic development at regional level is the urbanization of the population. In a certain aspect, however, this factor has a negative impact on the overall development of the other territories as it is an indicator of a strong concentration of economic life as wells as active population in urban areas and leads to delays in the development of other regions and areas outside major urban centers. In fact, the per capita GDP dependence is the result of the above-mentioned trends of increasing distances between regions, to a great extent contrary to the expected cohesion. The next most important factor is the cost of acquiring tangible fixed assets per capita in BGN. This indicator again has a correlation of over 0,800 in individual years, and at some point the correlation coefficient reaches 0,900-0,920 (Figure 2). Following the factor of acquisition of tangible fixed assets is the number of nonfinancial corporations per 1000 people and foreign direct investment in non-financial sector enterprises. Their impact is very strong (over 0.758) (Figure 3). Although the number of enterprises appears to have a more mechanical impact, in fact, the increased number of enterprises per 1000 people is an indicator of economic recovery and development of a large number of small and medium-sized enterprises that accompany economic growth and respond to growing needs of the local population.

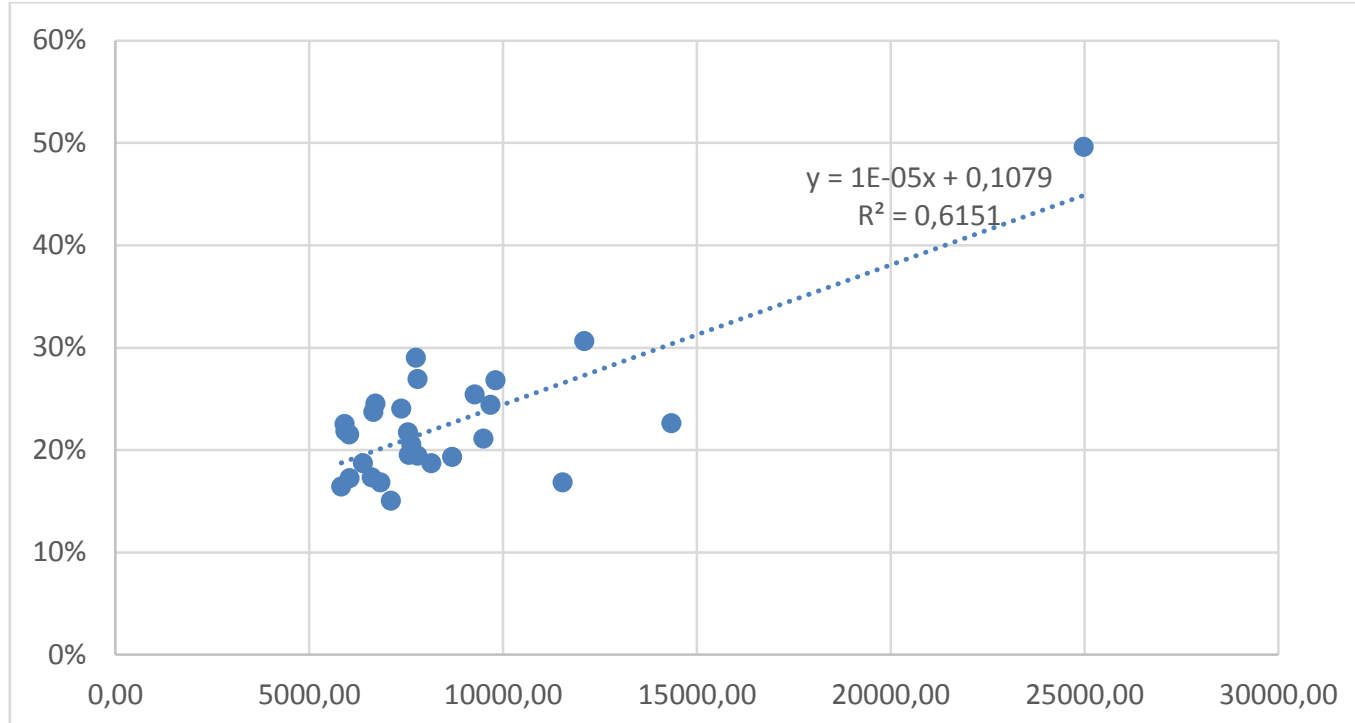

Figure 1. Correletaion between the relative share of the population aged between 25 and 64 with higher education (\%) and GDP per capita (data for 2014)

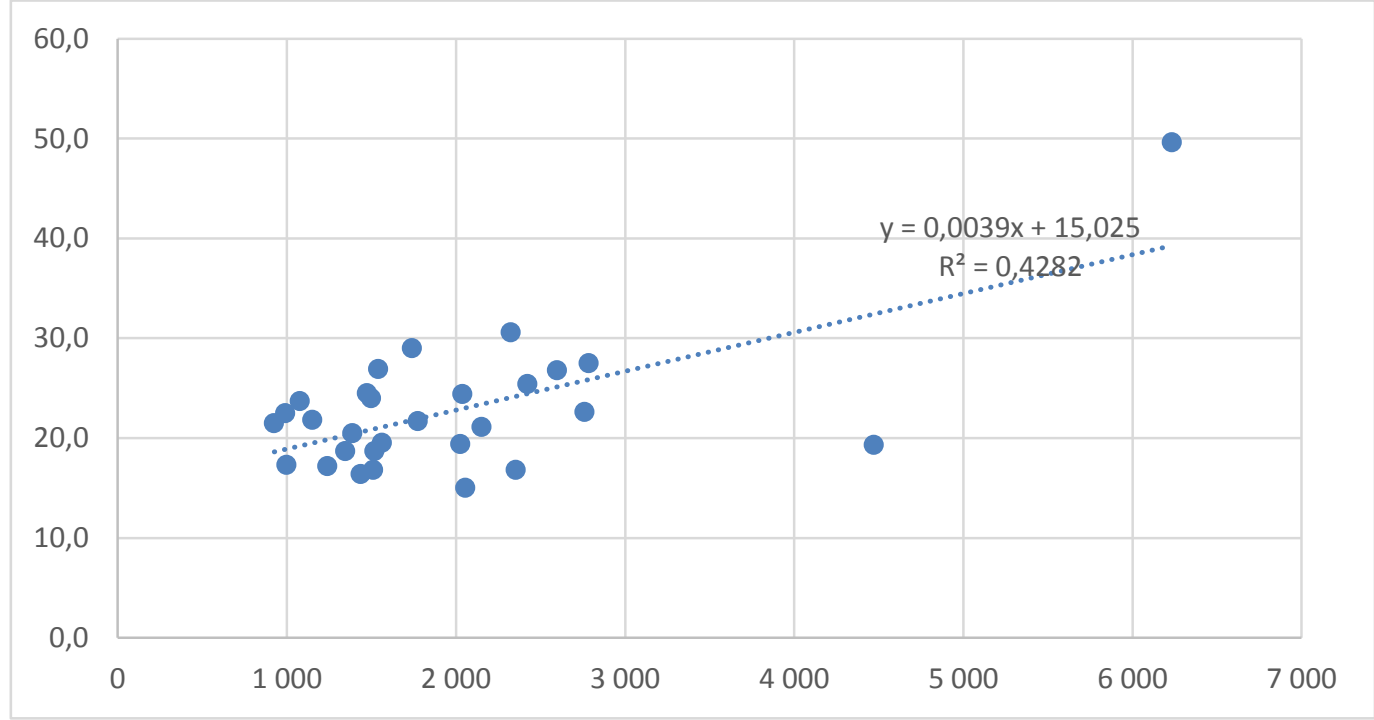

Figure 2. Correlation between the relative share of population aged between 25 and 64 with higher education (\%) and Expenses for acquisition of FTA per capita 


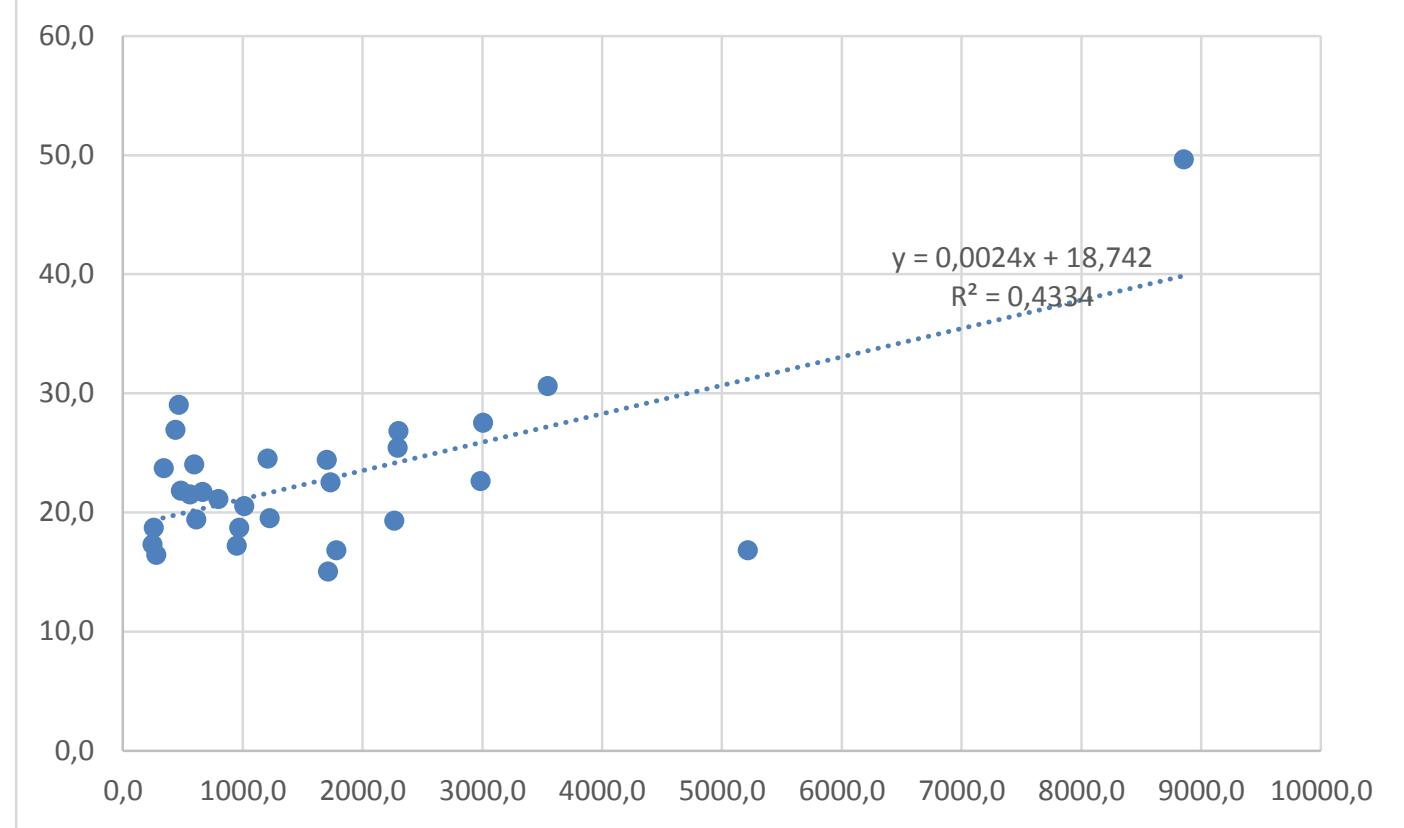

Figure 3. Correlation between the relative share of the population aged between 25 and 64 with higher education (\%) and FDI in non-financial enterprises with accumulation, EUR/person

Of course, despite the high correlation coefficient, we can not believe that the educational structure of the population may be a self-sufficient growth factor at regional level. Although we have a correlation, we can not say that we have clear evidence that in this case it is an indication of a strong causal link. Or in other words, we can not expect that if we somehow "transfer" a large number of graduates to a particular territory, it would automatically lead to rapid economic growth. Moreover, there is also the reverse dependence - people with higher education are attracted and find jobs in well-developed areas and regions. The dependance is two-way. Education is a strong necessity, but not the only necessary condition for unleashing the potential of the regions. It should also be seen in relation to the other important prerequisites for economic development - investment, FTA and wealth, economic actors and competition leading to growth, as well as a good sociodemographic base - a population of active age. Each of these indicators correlates strongly with the educational level of the population of the individual regions - i.e. the higher the share of people with higher education in a given region, the higher the investment in FTA and the higher the number of enterprises in the non-financial sector. At the same time, we clearly see in the analysis that the share of people with low education (both basic and lower) also has an impact, but this time negatively, on economic development - the smaller the share of people with low education, the higher GDP per capita figures.
If we have to summarize the influence of the different factors that complement the importance of education, they are: capital inflow, investment in assets (including technology and innovation), a good social and demographic base with a strong focus on human capital development.

In other words, the attraction of foreign investment or any investment must go hand in hand with investment in human capital and more specifically in investment in education. This investment, however, must be accompanied by a very high quality of education and a clear link to the needs of the labor market (5). That is why not only investments measured as money or as a share of GDP are important, but also investments in what area of education. The main reason why investments in higher education can increase growth is that such investments are likely to stimulate additional R\&D investments, thus fostering technological innovation.

\section{CONCLUSION AND RECOMMENDATIONS}

The big question that remains with the design of policies at local level is how regions that have lost their positions (the number of enterprises has dropped, there is a stagnation in the share of the population with higher education, human capital has to catch up with the average for the country, investments have diminished) can improve their economic development and attract young and educated professionals. No intervention can be made only in one direction or offset only one side of 
the equation. In order to achieve good economic development, efforts must be multidimensional and intervene on each of the aforementioned factors of economic development. They should be both human capital and attracting investments, and in creating a favorable environment, including administrative services, appropriate infrastructure and business conditions. The attraction of young and educated professionals is a very important factor for achieving good economic development, but with a critical mass of business initiatives that can attract and retain these specialists.

The strong distances between regions are now an additional barrier to be overcome because, once occurred, they have an additional impact on the economic actors' choice to invest in. Accumulation of human capital is a major source of productivity growth, which in turn has a positive impact on regional development. Therefore, a good mix of regional development policies should start with investments in human capital as far as these investments are not swift and deliver results over time. They must, of course, be accompanied by policies that encourage investments and enable good technological development for businesses.

\section{REFERENCES}

1. Hausmann, R, Rodrik, D, and A. Velasco, Growth Diagnostics, Mimeo, Harvard University, 2005

2. Spence, M., The Growth Report: Strategies for Sustained Growth and Inclusive Development, World Bank, 2009

3. Aghion, P., L. Boustan, C. Hoxby, and J. Vandenbussche, Exploiting States' Mistakes to Identify the Causal Impact of Higher Education on Growth, NBER conference paper, http://www.nber.org/confer/2005/si2005/ed /hoxby.pdf , 2005

4. Aghion, P., P. Howitt, The economics of growth, 2009 Massachusetts Institute of Technology

5. Acemoglu, Daron, Training and Innovation in an Imperfect Labor Market, 1997 